\title{
Modelling the Influence of Layout on Overheating Risk of London Flats
}

\author{
Andrea Vallejo Espinosa ${ }^{1}$, Phil Symonds ${ }^{1}$, Giorgos Petrou ${ }^{2}$ \\ ${ }^{1}$ Institute of Environmental Design and Engineering, Bartlett School of Environment, Energy and \\ Resources, University College London, Central House, 14 Upper Woburn Plc, London WC1H \\ ONN, United Kingdom \\ ${ }^{2}$ UCL Energy Institute, University College London, Central House, 14 Upper Woburn Plc, London \\ WC1H 0NN, United Kingdom
}

\begin{abstract}
An analysis of overheating levels corresponding to building morphology yielded the modelling uncertainty due to the geometry and layout of two-bedroom flats in London, England. A new method is introduced, which collates information on various flat layouts in the current London housing stock. To ensure an unbiased sample was selected, dwellings were chosen randomly, yielding twelve flats in and around inner London. Dynamic thermal simulations were performed using EnergyPlus to determine individual dwellings' overheating risk. The results described the influence of geometry and layout configuration on overheating risk, which has rarely been analysed in previous studies. Irregular façades led to higher overheating levels in the set-back part of the building. Default configurations were used to model basecase archetypes, with further simulations performed to study the effects of orientation, ceiling heights and window glazing fractions. Compared with these factors, bigger differences between mean operative temperatures of flats were due to layout, with $3.5^{\circ} \mathrm{C}$ in bedrooms, $1.5^{\circ} \mathrm{C}$ in living rooms and $2.2{ }^{\circ} \mathrm{C}$ in kitchens.
\end{abstract}

\section{Introduction}

The massive release of greenhouse gases due mainly to human activities is a global threat that has led to warming oceans and drying land and forests (Droege, 2008). Following the 2015 Paris Agreement, participating countries set a target to limit temperature increase to below $2{ }^{\circ} \mathrm{C}$ above pre-industrial levels. In the UK, the residential sector is responsible for $14 \%$ of direct greenhouse gas emissions (Bell et al., 2016). Additionally, from listed energy supply discharges, the residential sector constitutes $7 \%$ of the emissions, which means that a total of $21 \%$ of the emissions are attributed to the residential sector. Heating and cooking are the main sources of greenhouse gas emissions in the residential sector. In fact, temperature regulation was the primary reason for a $4 \%$ increase in emissions between 2015 and 2016 (BEIS, 2018).

There are over 26 million dwellings in the UK housing stock, of which only $10 \%$ have achieved high Energy Efficiency Ratings (Randall, 2011). Improving the existing stock is quite challenging, especially considering that more than $85 \%$ of the current building stock in the UK will still be in use in 2050 (Ravetz, 2008; CIOB, 2013). An increase in heatwave events resulting from global warming will bring negative health effects. The high temperatures during the devastating 2003 European heatwave resulted in 2000 excess deaths in England in a 10-day period (PHE, 2018). These temperatures will likely be considered normal by 2040 (PHE, 2018). Increasing attention has been placed on dealing with severe summer temperatures. The WHO (1987) recommended a comfort zone range between $18{ }^{\circ} \mathrm{C}$ to 24 ${ }^{\circ} \mathrm{C}$, because it offers little thermal threat to sedentary people under appropriate conditions.

Previous studies using dynamic thermal simulations found that buildings in London with lightweight constructions had a higher potential for overheating (Peacock, Jenkins and Kane, 2010). Kolokotroni and Giridharan (2008) evaluated the influence of buildings' physical characteristics on overheating risk, concluding that the biggest factor was surface albedo, with smaller values yielding a lower air temperature. The second largest variable was thermal mass.

The impact of different occupancy profiles on overheating has also been analysed in previous studies, Weng (2017) found that night ventilation is more effective than daytime ventilation and that for present climate scenarios different window opening profiles reduce overheating. However, this strategy will have little effect in 2050 under projected weather scenarios. Two occupancy profiles are typical used in simulations. Porritt et al., (2013) showed that pensioners' occupancy profile experienced double exposure to overheating on the number of degree hours over $26^{\circ} \mathrm{C}$ and $28{ }^{\circ} \mathrm{C}$ for bedrooms and living rooms respectively than the family occupancy profile during daytime. Additionally, Mavrogianni et al., (2014) as part of the AWESOME project identified that pensioners were exposed to overheating for several more hours than the family. Aragon et al., (2017) found that the two typical occupancy profiles used, were found to represent only $19 \%$ of UK's population and developed seven other profiles for study. The second most common profile used in simulations the 'elderly couple' was deemed the most vulnerable group. Therefore, this profile was used in this project to represent one of the worst occupancy scenarios. This study aimed to bridge the research gap found in previous works that have not analysed the impact of layout and geometry on the overheating risk of dwellings. Existing two-bedroom flats in London were used in this study to evaluate the overheating risk of different geometry and layout configurations. 


\section{Methods}

This study focused on two-bedroom flats in London, to limit the scope of this work while ensuring that it reflected the real state of London's housing stock. They have been identified as one of the worst performing dwelling types in numerous studies (Symonds et al., 2017, 2016; Kolokotroni et al., 2010; Oikonomou et al., 2012). Flats have the highest overheating risk and an increasing presence in London. In private and public sectors, a greater incidence of two-bedroom housing has been reported by the Housing Space Standards, currently constituting $80 \%$ of the dwellings being built (Drury et al., 2006; Gleeson and Patel, 2017). Two-bedroom flats represent $60 \%$ of the total flat production (Drury et al., 2006).

\section{Selection of sources of information}

First, an online search was conducted on property websites to consolidate available information on current flats in London. Additionally, various real estate websites were identified and compared. This information was publicly available and represented real properties within London. Moreover, this strategy allowed large quantities of information to be acquired quickly, rendering it the most effective means for data collection. Each online source was ranked based on the presence of search filters, size of the data-set and availability of floorplans and location information. This enabled a more accurate identification of properties. Employing this method, the number of properties 'for sale' and 'to rent' were isolated. Only three websites: Zoopla, Right Move and Prime Location, fulfilled all selection criteria, and hence were chosen for this research.

\section{Selection of sampling size}

The sample size was based on the time and difficulty involved in generating models and simulating each building. To remove any biases, properties were randomly selected to reflect London's two-bedroom flats. Two properties were randomly selected from every 'for sale' and 'to rent' category of each chosen website, yielding a total of 12 floorplans. All properties had an identical probability of being selected for the study. The randomised selection process was conducted as follows:

1. Visiting the three websites mentioned and applying selection criteria produced numerous pages comprising the entire list of two-bedroom flats.

2. A random value between 1 and the total number of pages was generated, and the flat selected was the first property on that page which met all requirements, such as the need for floorplans to be included in the listing.

The selected property had to be located on the middle floor of the building. This was to avoid additional external factors affecting the indoor environment of the flat. Top flats were excluded for two reasons: firstly, Drury et al., (2006) suggested that penthouses may have significantly larger areas; secondly, Oikonomou et al., (2012) showed that top-flats performed worse than middle-floor flats. Only the middle floor within a three-story building was simulated for consistency.

The floorplan collected for each dwelling was compared with written descriptions, and with corresponding images, for corroboration. If the property selected did not fulfil all parameters, another property with the same criteria was selected. Information on each property was collected, indexed and used to develop a set of floorplans in CAD to confirm dimensions. The location of the twelve properties are mapped as shown in Figure 1. It is clearly seen that more than $90 \%$ of properties were located within inner London, with just one property located in an outer London borough.

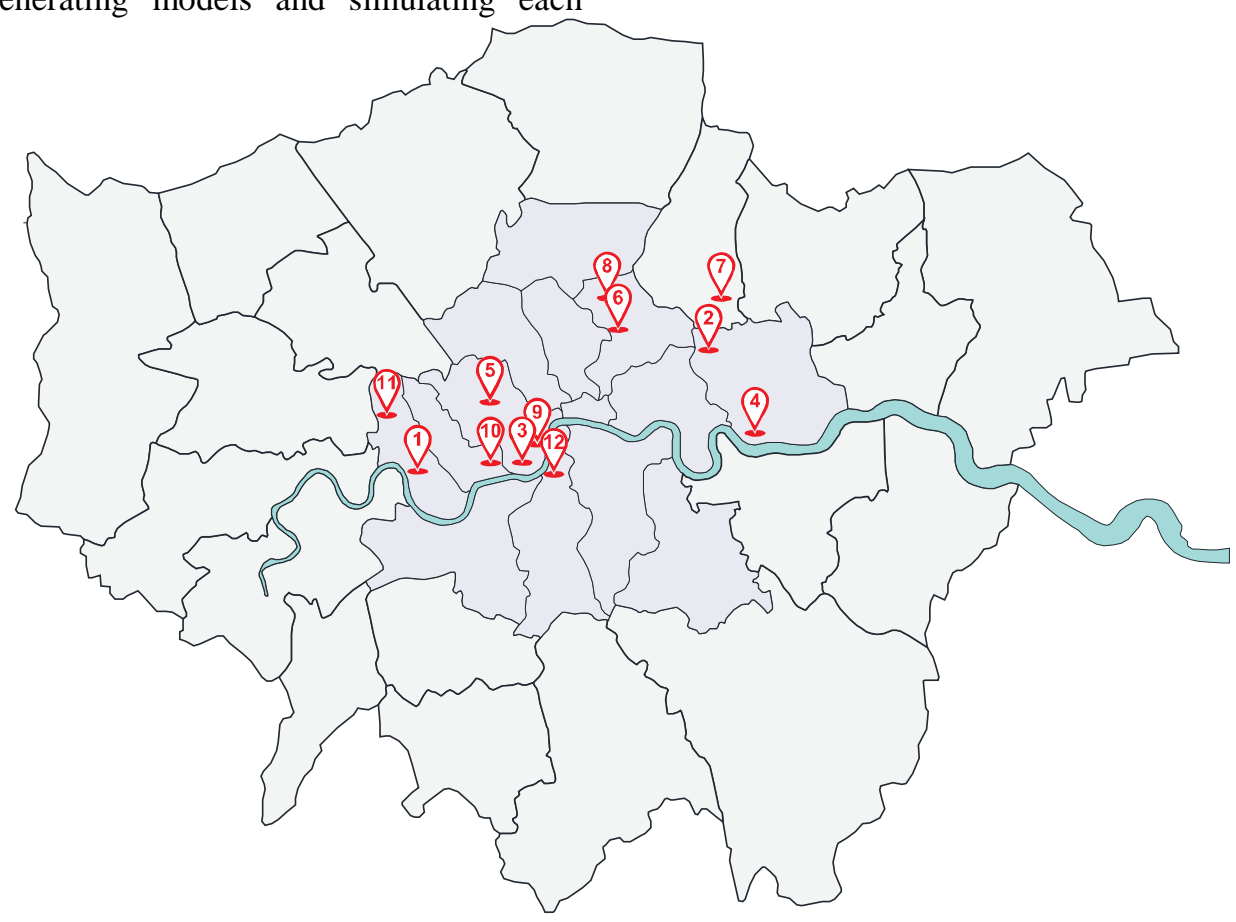

Figure 1: Location of properties within London's inner and outer boroughs. 


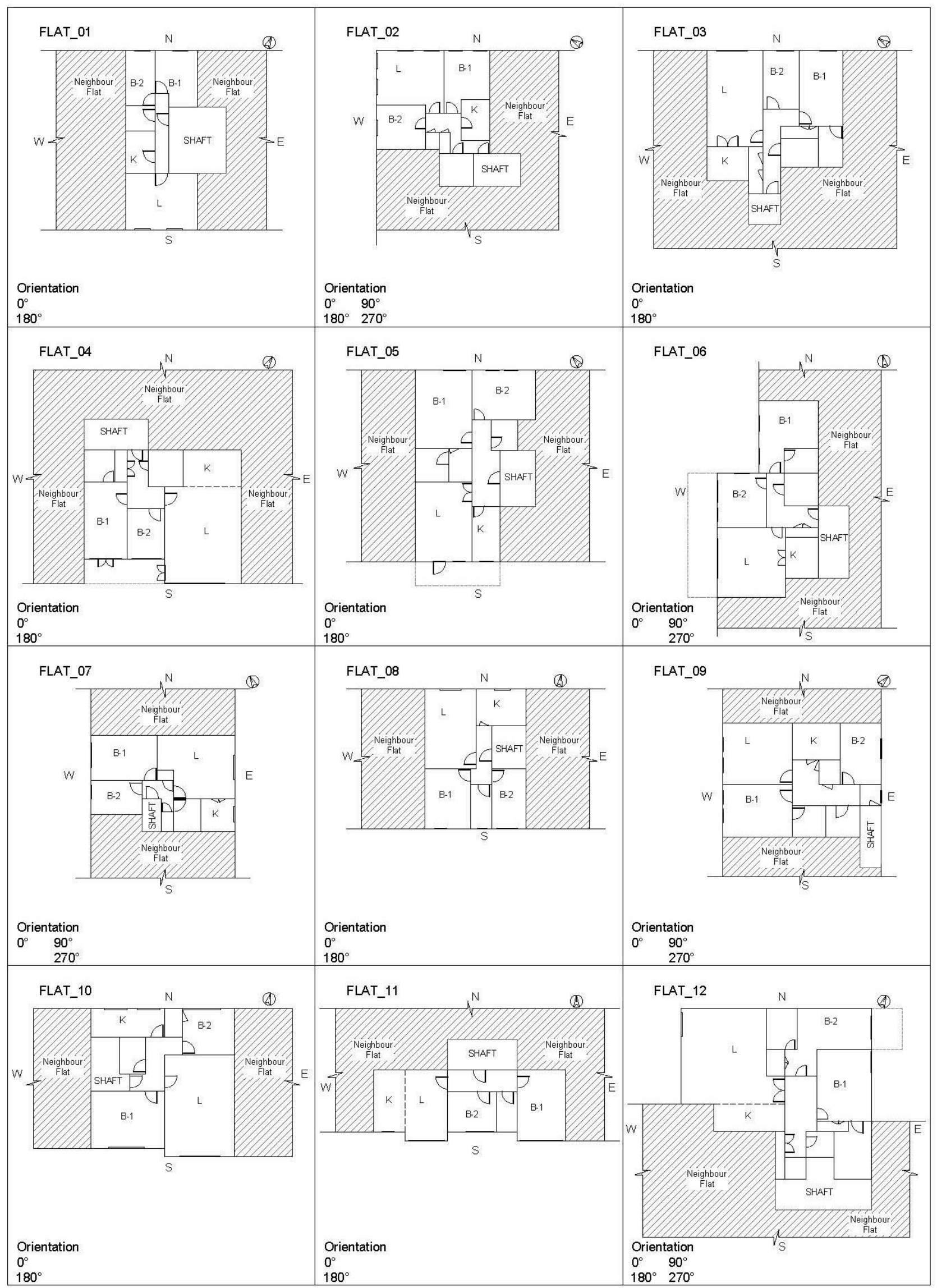

Figure 2: Building layouts, with the true north indicated by the arrow in the top right corner. Orientations simulated are given in the bottom left corner of each model. The four cardinal points $(N-S-E-W)$ are also provided. The floor plans represent bedrooms 1 and $2(B-1, B-2)$, living room $(L)$, kitchen $(K)$, and the shaft at the entrance of each flat. 


\section{Dwelling Layouts}

The flats' internal layouts were recreated in CAD using their floor plans, and verified using images included in the listing. All zones were characterised by simple rectangular prisms and cubic shapes, while ensuring that their basic form and geometry were not affected. Figure 2 shows the layouts for the 12 flats used in this study. Approximate ceiling heights were determined from images of internal spaces using a door height of $2.10 \mathrm{~m}$ taken from widely accepted door dimensions (Neufert, 1995, p.169). This yielded an average ceiling height of 2.4 $\mathrm{m}$, which was then assumed for all dwellings to disregard the effect of ceiling height and ensure that layout configuration was the only dependent variable. Window dimensions were calculated using floorplans, and again using relative proportions obtained from site images. Ratios of window to wall areas were calculated by dividing the former by the latter. Flat orientations (NorthSouth-East-West, coinciding with but not strictly aligned with true orientation) were determined from flat location, and true north indicated next to each floorplan (Figure 2). Since flats are typically part of a larger building, zones representing nearby flats were simulated to represent true conditions, with adiabatic heat transfer assumed between neighbouring zones. Where a window or other means of ventilation was not present, an adjoining flat was inferred. Building internal connections such as stairs and lifts were represented by the shaft and assumed at the entrance to flats. The ground and top floors were simulated using building representations matching the area of the designed middle floor. Following this, an input data spreadsheet was created with the coordinates and dimensions of every room, along with the building characteristics. These data were input to an in-house software utility (EnergyPlus Generator - EPG) to develop IDF files which were simulated in EnergyPlus version 8.8.0 (U.S. DOE BTO, 2017), employing the methodology used by Symonds et al., (2016).

\section{Occupancy schedules}

Occupancy patterns were selected from Symonds et al., (2016), based on the work of Mavrogianni et al., (2014). Flats were determined to present the highest risk exposure to the elderly of any building type. 'Pensioners' staying mainly indoors were identified as the most vulnerable occupants, and thus in most 'need' of being modelled. This occupancy schedule was kept static for all model runs, to ensure that the influence of internal heating was the same for each building layout. A detailed hourly schedule of pensioner couples is described in Mavrogianni et al., (2014).

\section{Weather files}

Weather data were chosen to represent inner London's climate conditions. For this study, a 'current' single DSY (Design Summer Years) weather file for Islington was used, acquired from the PROMETHEUS project (Eames, Kershaw and Coley, 2011), to assess the influence of layouts under the same climate. Overheating risk was simulated for the warmest period between May to September as recommended in TM59 (CIBSE, 2017).

\section{Simulation parameters}

Building fabric characteristics were defined based on previous studies on the dwelling archetype. (Symonds et al., 2016; Oikonomou et al., 2012; Mavrogianni et al., 2012, 2014). Flats at the middle level were modelled, along with the adjoining building (which had the same area and height as the property under study) to include the effect of sunlight screening for shading, applying the same methodology used by Taylor et al., (2015). Multiple parameters were simulated including: orientations, two different ceiling heights $(2.4 \mathrm{~m}, 2.8 \mathrm{~m})$ and two different window ratios (true, 0.295). The flats were initially simulated using the true orientation. Further, the living room and bedrooms were studied under north and south alignments to understand the impact of building configuration while excluding the sun exposure factor. This series of simulations were performed to better understand the role of layouts on overheating risk.

\section{Dwelling characteristics}

Since the factor under study is building layout, the building characteristics in Table 1 were kept constant for all simulations. Room areas were determined from the generated layouts and the average flat size was calculated to be $69 \mathrm{~m}^{2}$

\section{Table 1: Building input characteristics for simulations.}

\begin{tabular}{|c|c|}
\hline Permeability (m3/h/m2 @ 50 Pa) & 15 \\
\hline Window Open and Heater Threshold $\left({ }^{\circ} \mathrm{C}\right)$ & 22 \\
\hline Gains Factor & 0.4 \\
\hline $\mathrm{CO}_{2}$ Emission & 0.07 \\
\hline Extract Factor & 0.5 \\
\hline General Deposition Velocity & 1.8 \\
\hline Albedo Factor & 0.3 \\
\hline Walls U-Value $\left(\mathrm{W} / \mathrm{m}^{2} \mathrm{~K}\right)$ & 1.6 \\
\hline Roof U-Value $\left(\mathrm{W} / \mathrm{m}^{2} \mathrm{~K}\right)$ & 1.5 \\
\hline Window U-Value $\left(\mathrm{W} / \mathrm{m}^{2} \mathrm{~K}\right)$ & 2 \\
\hline Floor U-Value $\left(\mathrm{W} / \mathrm{m}^{2} \mathrm{~K}\right)$ & 0.6 \\
\hline
\end{tabular}

\section{TM59 overheating risk assessment criteria}

The TM59 (CIBSE, 2017) is a method for assessing the overheating risk in dwellings based on dynamic thermal modelling, which uses the TM52 (CIBSE, 2013) basis of design comfort criteria. According to CIBSE Guide A (2015), living areas are considered to be overheated when their temperature exceeds an operative temperature of $28{ }^{\circ} \mathrm{C}$ for more than $1 \%$ of annual occupied hours, and bedrooms when their temperature exceeds $26^{\circ} \mathrm{C}$. Moreover, to maintain sleep quality a maximum bedroom temperature of $24{ }^{\circ} \mathrm{C}$ is recommended. The TM59 methodology was designed focusing on flats, however, it can provide a baseline for overheating risk assessment in all domestic dwellings. It requires a suitable sample, detailed zoning and to model building characteristics in detailed for simulations. In this study, the dwelling characteristics previously explained and the occupancy pattern of two pensioners was used instead of the one required for the evaluation. The flats were analysed under TM52 Criteria for predominantly naturally ventilated homes. The resulting hourly operative temperatures were used to analyse whether individual flats passed the assessment. 


\section{Results}

\section{Simulations using the true building orientation}

Table 2 shows the average mean and maximum operative temperatures modelled over the summer period. Overall, all flats displayed maximum temperatures over $28{ }^{\circ} \mathrm{C}$ in at least one room. The maximum temperatures surpassed $31{ }^{\circ} \mathrm{C}$ in four bedrooms from different flats $\left(4^{\text {th }}, 6^{\text {th }}, 10^{\text {th }}\right.$, $11^{\text {th }}$ ), that all had an irregular façade (i.e. non-rectangular) with an adjacent room protruding from the building façade. Building shape and cross ventilation had an important effect on overheating risk. Also, the inclusion of a shading device (overhang) had a significant effect on buildings with regular configurations, as seen by comparing flats 4 and 6 . Additionally, Table 2 shows the percentage of time when the temperature of rooms where higher than the comfort limit recommended by WHO (24 $\left.{ }^{\circ} \mathrm{C}\right)$ and by CIBSE Guide A $\left(26{ }^{\circ} \mathrm{C}\right.$ for bedrooms and 28 ${ }^{\circ} \mathrm{C}$ for other living spaces). Spaces displayed temperatures over $24{ }^{\circ} \mathrm{C}$ an average of $17 \%$ of time in bedrooms, $24 \%$ in living rooms and $79 \%$ in kitchens. Temperatures over $26{ }^{\circ} \mathrm{C}$ were displayed an average of $5 \%$ of time in bedrooms and temperatures over $28{ }^{\circ} \mathrm{C}$ an average of $1.4 \%$ in living rooms and $33 \%$ in kitchens. The average duration of temperatures above $24{ }^{\circ} \mathrm{C}$ in bedrooms was 9.9 hours with a median of $11 \mathrm{~h}$, and in living rooms an average of $8.8 \mathrm{~h}$ with a median of $5 \mathrm{~h}$.

\section{Simulation results using different building} orientations, heights and glazing area fraction

Extra simulations were carried out on the twelve flats and a comparison chart for bedrooms is shown in Figure 3. Varying ceiling height had little effect on the overall thermal performance of the flats. Increasing glazing fraction by around 0.10 yielded a corresponding increase of between $0.22{ }^{\circ} \mathrm{C}$ to $0.27{ }^{\circ} \mathrm{C}$ in rooms facing north. However, for a room facing west the temperature

Table 2: Base-case max and mean operative temperatures over the summer period for all rooms. Percentage of time when temperature passed $24^{\circ} \mathrm{C}$ limit recommended by $\mathrm{WHO}$ and $26^{\circ} \mathrm{C} / 28^{\circ} \mathrm{C}$ recommended by CIBSE Guide A.

\begin{tabular}{|c|c|c|c|c|c|c|c|c|c|c|c|c|c|c|c|}
\hline & $\begin{array}{c}\text { Flat } \\
01\end{array}$ & $\begin{array}{c}\text { Flat } \\
02\end{array}$ & $\begin{array}{c}\text { Flat } \\
\mathbf{0 3} \\
\end{array}$ & $\begin{array}{c}\text { Flat } \\
04\end{array}$ & $\begin{array}{c}\text { Flat } \\
\text { 05 } \\
\end{array}$ & $\begin{array}{c}\text { Flat } \\
06\end{array}$ & $\begin{array}{c}\text { Flat } \\
\text { 07 } \\
\end{array}$ & $\begin{array}{c}\text { Flat } \\
08\end{array}$ & $\begin{array}{c}\text { Flat } \\
09 \\
\end{array}$ & $\begin{array}{c}\text { Flat } \\
10 \\
\end{array}$ & $\begin{array}{c}\text { Flat } \\
11 \\
\end{array}$ & $\begin{array}{c}\text { Flat } \\
12 \\
\end{array}$ & $\begin{array}{c}\text { Pre } \\
1990 \\
\end{array}$ & $\begin{array}{l}\text { Post } \\
1990 \\
\end{array}$ & $\begin{array}{r}\text { STD } \\
01-12 \\
\end{array}$ \\
\hline \multicolumn{16}{|c|}{ Bedroom 1 } \\
\hline Max & 25.0 & 25.9 & 25.0 & 29.3 & 25.0 & 32.6 & 28.8 & 28.0 & 28.5 & 33.0 & 29.9 & 26.5 & 26.5 & 27.6 & 2.80 \\
\hline Mean & 20.4 & 21.2 & 20.3 & 21.8 & 20.3 & 21.5 & 21.3 & 21.4 & 21.2 & 22.4 & 21.4 & 21.0 & 21.6 & 22.1 & 0.63 \\
\hline$\% \mathrm{~h}>24^{\circ} \mathrm{C}$ & $8 \%$ & $27 \%$ & $7 \%$ & $19 \%$ & $6 \%$ & $25 \%$ & $1 \%$ & $19 \%$ & $21 \%$ & $35 \%$ & $25 \%$ & $19 \%$ & $4 \%$ & $11 \%$ & $\mathrm{n} / \mathrm{a}$ \\
\hline$\% \mathrm{~h}>26^{\circ} \mathrm{C}$ & $0 \%$ & $5 \%$ & $0 \%$ & $2 \%$ & $0 \%$ & $13 \%$ & $0 \%$ & $4 \%$ & $6 \%$ & $20 \%$ & $10 \%$ & $4 \%$ & $0 \%$ & $1 \%$ & $\mathrm{n} / \mathrm{a}$ \\
\hline \multicolumn{16}{|c|}{ Bedroom 2} \\
\hline Max & 25.1 & 27.3 & 25.2 & 32.3 & 25.3 & 29.6 & 29.4 & 27.5 & 28.7 & 27.1 & 32.3 & 25.5 & 27.5 & 9.5 & 2.58 \\
\hline Mean & 20.1 & 20.5 & 20.4 & 22.5 & 19.7 & 20.5 & 20.8 & 20.8 & 21.3 & 20.8 & 22.0 & 20.1 & 22.4 & 23.3 & 0.82 \\
\hline$\% \mathrm{~h}>24^{\circ} \mathrm{C}$ & $13 \%$ & $7 \%$ & $9 \%$ & $27 \%$ & $5 \%$ & $20 \%$ & $1 \%$ & $18 \%$ & $37 \%$ & $15 \%$ & $35 \%$ & $12 \%$ & $12 \%$ & $32 \%$ & $\mathrm{n} / \mathrm{a}$ \\
\hline$\% \mathrm{~h}>26^{\circ} \mathrm{C}$ & $1 \%$ & $0 \%$ & $1 \%$ & $9 \%$ & $0 \%$ & $6 \%$ & $0 \%$ & $3 \%$ & $15 \%$ & $2 \%$ & $19 \%$ & $1 \%$ & $1 \%$ & $8 \%$ & $\mathrm{n} / \mathrm{a}$ \\
\hline \multicolumn{16}{|c|}{ Living room } \\
\hline Max & 28.0 & 28.2 & 26.5 & 30.1 & 26.9 & 28.6 & 27.6 & 26.9 & 29.3 & 28.8 & 29.5 & 29.3 & 27.5 & 30.1 & 1.16 \\
\hline Mean & 21.4 & 21.0 & 21.1 & 21.7 & 21.0 & 21.1 & 21.6 & 21.1 & 21.6 & 21.6 & 21.9 & 21.3 & 21.6 & 22.5 & 0.29 \\
\hline$\% \mathrm{~h}>24^{\circ} \mathrm{C}$ & $28 \%$ & $9 \%$ & $26 \%$ & $20 \%$ & $20 \%$ & $22 \%$ & $10 \%$ & $14 \%$ & $28 \%$ & $17 \%$ & $29 \%$ & $65 \%$ & $19 \%$ & $31 \%$ & $\mathrm{n} / \mathrm{a}$ \\
\hline$\% \mathrm{~h}>28^{\circ} \mathrm{C}$ & $1 \%$ & $0 \%$ & $0 \%$ & $1 \%$ & $0 \%$ & $1 \%$ & $0 \%$ & $0 \%$ & $1 \%$ & $1 \%$ & $1 \%$ & $8 \%$ & $0 \%$ & $3 \%$ & $\mathrm{n} / \mathrm{a}$ \\
\hline \multicolumn{16}{|c|}{ Kitchen } \\
\hline Max & 32.5 & 32.7 & 31.7 & 30.8 & 28.6 & 32.2 & 30.0 & 28.9 & 31.5 & 28.5 & 29.6 & 30.9 & 28.9 & 29.0 & 1.51 \\
\hline Mean & 23.5 & 23.7 & 22.8 & 22.6 & 21.6 & 23.1 & 22.4 & 21.5 & 23.2 & 21.5 & 21.9 & 22.4 & 22.1 & 22.0 & 0.77 \\
\hline$\% \mathrm{~h}>24^{\circ} \mathrm{C}$ & $98 \%$ & $98 \%$ & $93 \%$ & $62 \%$ & $87 \%$ & $92 \%$ & $40 \%$ & $37 \%$ & $93 \%$ & $30 \%$ & $43 \%$ & $90 \%$ & $43 \%$ & $45 \%$ & $\mathrm{n} / \mathrm{a}$ \\
\hline$\% \mathrm{~h}>28^{\circ} \mathrm{C}$ & $63 \%$ & $66 \%$ & $44 \%$ & $10 \%$ & $37 \%$ & $44 \%$ & $6 \%$ & $5 \%$ & $47 \%$ & $4 \%$ & $6 \%$ & $47 \%$ & $7 \%$ & $6 \%$ & $\mathrm{n} / \mathrm{a}$ \\
\hline
\end{tabular}

increased by $1.70{ }^{\circ} \mathrm{C}$. A direct connection was observed between glazing area and changes in temperature. Furthermore, windows facing south and west displayed a greater corresponding reduction in temperature with reduced glazing fractions. Variations in glazing fraction among bedrooms facing north had little to no effect on the overheating performance of the rooms. The northoriented façade represents rooms without sun exposure, while the south-oriented façade is under direct sunlight influence. Maximum operative temperatures ranged from $25{ }^{\circ} \mathrm{C}$ to $27.5^{\circ} \mathrm{C}$ over May to September when facing north and from $26.8^{\circ} \mathrm{C}$ to $35.2^{\circ} \mathrm{C}$ when facing south. For living rooms, the maximum temperature ranged from $26.5^{\circ} \mathrm{C}$ to $28.3{ }^{\circ} \mathrm{C}$ and $27{ }^{\circ} \mathrm{C}$ to $30.1{ }^{\circ} \mathrm{C}$ for north and south orientations respectively.

\section{Simulation results analysed under the TM59 criteria}

Assessment criteria from TM59 were applied to buildings simulated under the previously described building characteristics and occupancy schedules. Moreover, it was tested under the Islington 'current' DSY weather file during the period of May to September to determine whether dwellings are at risk of overheating. The difference of temperature greater or equal to one degree (K) should not be more than three per cent of occupied hours to comply with criterion 1 used in this analysis. Bedrooms located in the second layer of an irregular façade (i.e. non-rectangular) did not pass the criteria as seen in Table 3. Five out of twelve kitchens did not pass, all of which were located in the interior of the dwelling without window access. In flats $4^{\text {th }}$ and $12^{\text {th }}$ the kitchens were also internally, and were simulated using same conditions from Table 1. However, those were open plan kitchens directly attached to the living room with an area greater than $30 \mathrm{~m}^{2}$, which enabled them to pass. Kitchens without windows show higher overheating risk. 


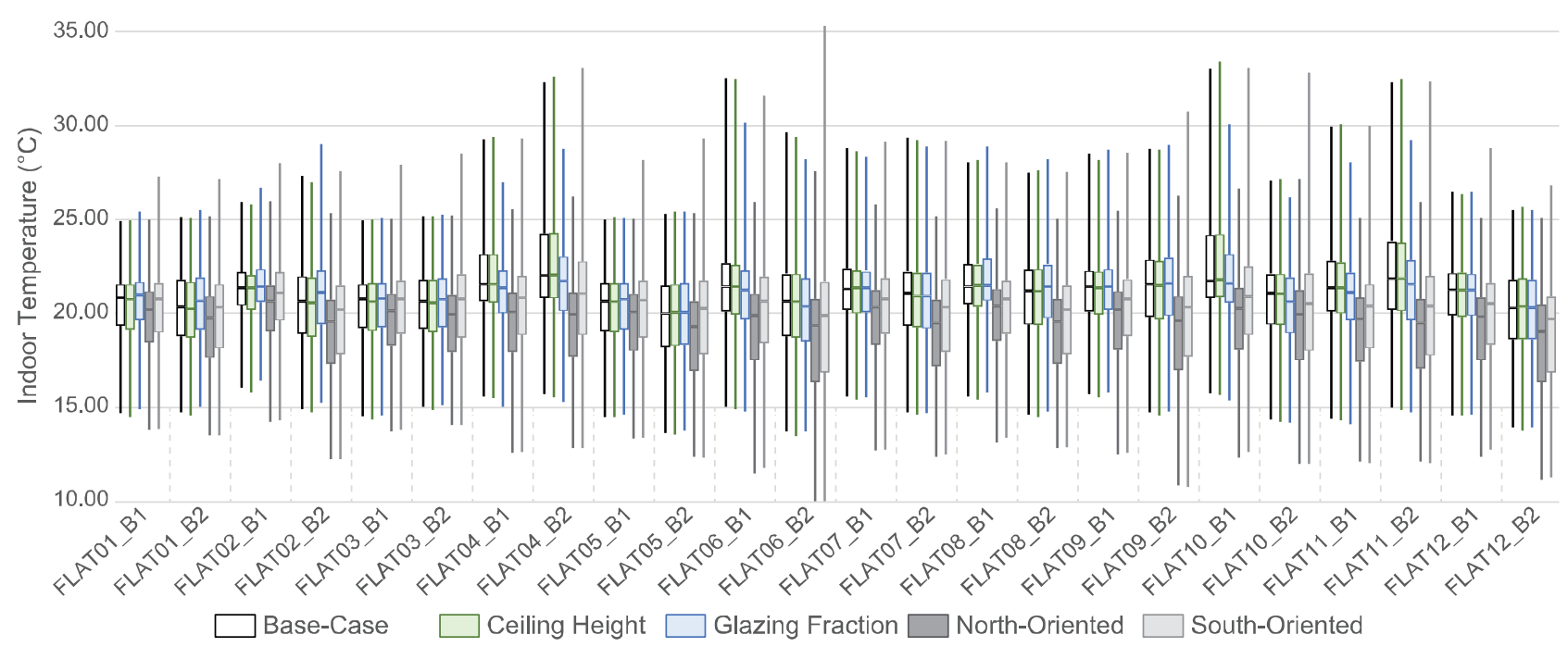

Figure 3: Boxplots showing the modelled hourly operative temperature range for bedrooms 1 and 2 by flat over summer (May-Sep). Whiskers show the highest and lowest values; the width of the box shows the interquartile range (25th and 75th percentiles) and the central line represents the median value. The effect of varying various parameters (ceiling height, glazing fraction and north/south orientations) is illustrated.

Table 3: Overheating risk assessment. Percentage of hours. The zones in red colour did not pass the TM59 criteria.

\begin{tabular}{|c|c|c|c|c|c|c|c|c|c|c|c|c|}
\hline Zone & Flat01 & Flat02 & Flat03 & Flat04 & Flat05 & Flat06 & Flat07 & Flat08 & Flat09 & Flat10 & Flat11 & Flat12 \\
\hline Bedroom 1 & 0.00 & 0.00 & 0.00 & 0.44 & 0.00 & 2.78 & 0.30 & 0.00 & 0.03 & 4.33 & 0.65 & 0.00 \\
\hline Bedroom 2 & 0.00 & 0.00 & 0.00 & 4.22 & 0.00 & 0.25 & 0.25 & 0.00 & 0.00 & 0.00 & 3.49 & 0.00 \\
\hline Living room & 0.00 & 0.15 & 0.00 & 0.90 & 0.00 & 0.10 & 0.00 & 0.00 & 0.45 & 0.40 & 0.85 & 0.25 \\
\hline Kitchen & 9.65 & 11.06 & 5.78 & 1.51 & 0.15 & 7.39 & 0.75 & 0.20 & 5.68 & 0.20 & 0.95 & 2.06 \\
\hline
\end{tabular}

\section{Simulation results compared with previous studies}

Simulation results from this work were compared with results for corresponding dwelling archetypes modelled by Symonds et al., (2016) and is shown in Table 2. Layouts for typical two-bedroom flats with two configurations were used: pre-1990 and post-1990 buildings. This simulation was performed under the same building fabric characteristics, and using the same occupancy profiles and weather file as before. Living rooms of the flats exhibited a maximum operative temperature range between $26.5^{\circ} \mathrm{C}$ to $30.1{ }^{\circ} \mathrm{C}$, while the compared buildings had maximum operative temperatures of $27.5^{\circ} \mathrm{C}$ and $30.1^{\circ} \mathrm{C}$ for pre and post1990 respectively. For bedrooms there was a major discrepancy with pre and post-1990 properties registering maximum temperatures of $26.5^{\circ} \mathrm{C}$ and $27.6^{\circ} \mathrm{C}$, respectively. The average maximum temperature for flats was $28.1^{\circ} \mathrm{C}$. Additionally, it was found that $60 \%$ of kitchens were located internally within buildings, and without window access, hence ventilation profiles could not be applied. Kitchens in the twelve flats had a higher overheating risk than pre and post-1990 flats. However, a proper comparison was not possible since only $40 \%$ of the twelve simulated kitchens had window access, which both the pre and post-1990 flats possessed.

\section{Discussion}

This paper aimed at assessing the influence of dwelling layout, and the impact of orientation, ceiling height and window glazing fraction on the overheating risk of dwellings in London during the summer period from May to September. Modelling results displayed mean operative temperature variations between flats of $2.8^{\circ} \mathrm{C}$ for bedrooms, $0.9{ }^{\circ} \mathrm{C}$ for living rooms and $2.2^{\circ} \mathrm{C}$ for kitchens. The mean maximum temperatures between flats for bedrooms one was $28.1^{\circ} \mathrm{C}$ and for bedroom two was $28.0^{\circ} \mathrm{C}$ with a standard deviation of $2.8{ }^{\circ} \mathrm{C}$ and $2.6^{\circ} \mathrm{C}$ respectively. For living rooms, the mean maximum temperature was $28.3{ }^{\circ} \mathrm{C}$ with a standard deviation of $1.2{ }^{\circ} \mathrm{C}$; and for kitchens the maximum mean temperature reached $30.7{ }^{\circ} \mathrm{C}$ with a standard deviation of $1.5^{\circ} \mathrm{C}$. Differences of maximum temperatures between flats in bedrooms were $8^{\circ} \mathrm{C}$, these variations are larger than in living rooms $\left(3.6^{\circ} \mathrm{C}\right)$ and kitchens $\left(4.1^{\circ} \mathrm{C}\right)$. Analyses performed in this study revealed common overheating patterns in bedrooms, demonstrating a strong relationship between dwelling configuration and overheating risk. The mean operative temperature results showed that living rooms tend to perform worse than bedrooms, contrary to results from previous monitoring studies (Pathan et al., 2017; Wright, A, Young, A and Natarajan, 2005). This could be due to particular occupancy profile used in this work, as pensioners spend more time indoors than other occupant types.

The assessment under TM59 methodology was performed as indicative of comfort. Three bedrooms and five kitchens did not pass the criteria. Under this assessment is clearly seen that the overheated living areas were affected due to the geometry and layout of the dwelling. For instance, the three bedrooms that did not pass the criteria were the ones located in the second layer of the irregular façade. All five kitchens that did not pass the criteria were located in the internal part of the dwelling without 
window access. The authors of previous studies need to take this into account for further analysis.

A major finding of this study was that irregular façades (i.e. non-rectangular) results in temperature increases in the zone that is set back from the main façade, with greater variations observed when flats were not facing north. This could be due to reduced ventilation reaching this part of the dwelling. Mavrogianni et al., (2012), identified greater temperature variations due to building fabric changes than due to dwelling type. This study adds extra insight and demonstrates the impact of dwelling geometry and layout on the overall performance of dwellings. Greater variations in the range of mean and maximum temperatures could be attributed to the geometry of the façade. Another interesting finding is that the presence of sunlight shading devices has a much smaller effect on overheating when the building had an irregular façade geometry. Further work is required to determine retrofit measures that match specific building configurations.

\section{Limitations}

Only one DSY weather file, representing inner London was used in this work and the effect of varying weather conditions was not studied. There was some uncertainty regarding whether buildings allowing cross-ventilation performed better than single aspect building. The benefit of cross- ventilation was more obvious in north-south oriented dwellings than in flats oriented east-west. However, further simulations should be performed under different weather conditions to understand the influence of wind direction and pressure. Additionally, the impact of using different weather files on the performance of irregular façades has not been analysed.

The sample size used in this study is not statistically representative of the London housing stock. However, the flats analysed were randomly selected to guarantee an unbiased sample that represented the local dwelling stock. The accuracy of the chosen sample may be affected by the information available from online sources. To overcome this issue, existing images were used to corroborate information on the floorplan, windows and doors and to estimate ceiling heights. Because of the complexity of collecting information and modelling different layouts, only one dwelling type was used for this analysis.

\section{Further research}

This study has demonstrated the influence of dwelling layout and geometry on the overheating risk for twobedroom flats in London. This method could also be applied to other dwelling types to determine building features that affect their overall performance. Monitoring data may be collected to quantify the variation between real buildings and the ones used in simulations. Further work is required to test different shading options and their influence on irregular façades. Future research could also study factors besides overheating risk, such as indoor air quality and energy consumption.

\section{Conclusion}

This study set out to understand dwelling layout geometries and their propensity for overheating. Within the UK, two-bedroom flats in London were identified as having the highest overheating risk. This study used building simulation to determine some common building characteristics that may influence overheating in flats. For instance, an irregular façade led to higher overheating levels in the set-back part of the building. Kitchens within $60 \%$ of the flats studied were located in the interior without access to a window resulting in kitchens having higher temperatures than other rooms. The window glazing fraction tends to have a greater effect on bedrooms when the room is not facing north. Two ceiling heights, of $2.4 \mathrm{~m}$ and $2.8 \mathrm{~m}$, were used to compare the effect of height on performance, however, it was found that this had a minimal impact on overheating. Ceiling height had a greater impact in kitchens with no window access, where ventilation and shading strategies could not be applied. Living rooms had higher temperatures than bedrooms $70 \%$ of the time, and at least one bedroom per flat (except for flat 4) displayed lower mean temperatures than reported in the living room. A comparison of mean operative temperatures in bedrooms between the basecase and simulations involving varied ceiling heights and window glazing fractions showed mean differences of $0.09{ }^{\circ} \mathrm{C}$ and $0.15^{\circ} \mathrm{C}$ respectively. This was very small in comparison to a mean difference of $3.5^{\circ} \mathrm{C}$ due to layout. Differences in room area were important in kitchens with no access to a window. Likewise, the kitchen proximity to a large living room helped reduce overheating levels.

Previous studies developed theoretical archetypes which were expected to be representative of the London housing stock (Oikonomou et al., 2012). These archetypes have been used in multiple modelling studies in the past, which mapped out indoor environmental quality across the stock. However, test to determine whether or not these archetypes are indeed representative of the housing stock has not been established. This work quantified the variations in indoor temperatures due to the layout in a single flat type. The dwelling type representing flats in a previous work was compared against the flats used in this study. Differences in dwelling layout and geometry were observed, which affected thermal behaviour. These findings add to previous research and help increase accuracy to simulation-based studies.

\section{Acknowledgments}

The research was funded by the National Institute for Health Research Health Protection Research Unit (NIHR HPRU) [HPRU-2012-10016] in Environmental Change and Health at the London School of Hygiene and Tropical Medicine in partnership with Public Health England (PHE), and in collaboration with the University of Exeter, University College London, and the Met Office.

We gratefully acknowledge support from the Wellcome Trust for the 'Complex Urban Systems for Sustainability and Health' (CUSSH) project [award code 209387/Z/17/Z].

We thank the SENESCYT institution of the Ecuadorian Government for the postgraduate scholarship. 


\section{References}

Aragon, V., Gauthier, S., Warren, P., James, P. and Anderson, B. (2017). Developing English domestic occupancy profiles. Building Research \& Information, $1-19$.

BEIS (2018). Department for Business, Energy \& Industrial Strategy. 2016 UK Greenhouse Gas Emissions, final figures.

Bell, M., Bellamy, O., Gault, A., Hemsley, M., Smith, S., Thompson, M., Barrett, J., Pawar, N., Seera, P., Taylor, S., Westlake, S. and Wildeshaus, S (2016). UK climate action following the Paris Agreement.

CIBSE (2013). TM52: The limits of thermal comfort avoiding overheating in European buildings.

CIBSE (2015). Environmental Design CIBSE GUIDE A.

CIBSE (2017). TM59: Design methodology for the assessment of overheating risk in homes.

CIOB (2013). The Chartered Institute of Building. Submission to the All Party Parliamentary Group for Excellence in the Built Environment on inquiry into Sustainable Construction and the Green Deal.

Droege P. (2008). Urban Energy Transition: An Introduction, 655. University of Newcastle. Newcastle (Australia)

Drury, A., Watson, J., Broomfield, R., Levitt, D. and Tetlow, R. (2006). Housing Space Standards.

Eames, M., Kershaw, T. and Coley, D. (2011). Building Serv. Eng. Res. Technol. 32, 127-142.

Gleeson, J. and Patel, M. (2017). Housing in London: 2017.

Kolokotroni, M., Davies, M., Croxford, B., Bhuiyan, S. and Mavrogianni, A. (2010). A validated methodology for the prediction of heating and cooling energy demand for buildings within the Urban Heat Island: Case-study of London. Solar Energy 84, 22462255.

Kolokotroni, M. and Giridharan, R. (2008). Urban heat island intensity in London: An investigation of the impact of physical characteristics on changes in outdoor air temperature during summer. Solar Energy 82, 986-998.

Mavrogianni, A., Davies, M., Taylor, J., Chalabi, Z., Biddulph, P., Oikonomou, E., Das, P. and Jones, B. (2014). The impact of occupancy patterns, occupantcontrolled ventilation and shading on indoor overheating risk in domestic environments. Building and Environment 78, 183-198.

Mavrogianni, A., Wilkinson, P., Davies, M., Biddulph, P. and Oikonomou, E. (2012). Building characteristics as determinants of propensity to high indoor summer temperatures in London dwellings. Building and Environment 55, 117-130.

Neufert, P. (1995). Arte de Proyectar en Arquitectura. Editorial Gustavo Gili S.A. Barcelona (España).
Oikonomou, E., Davies, M., Mavrogianni, A., Biddulph, P., Wilkinson, P. and Kolokotroni, M. (2012). Modelling the relative importance of the urban heat island and the thermal quality of dwellings for overheating in London. Building and Environment 57, 223-238.

Pathan, A., Mavrogianni, A., Summerfield, A., Oreszczyn, T. and Davies, M. (2017). Monitoring summer indoor overheating in the London housing stock. Energy and Buildings 141, 361-378.

Peacock, A., Jenkins, D. and Kane, D. (2010). Investigating the potential of overheating in UK dwellings as a consequence of extant climate change. Energy Policy 38, 3277-3288.

Porritt, S., Cropper, P., Shao, L. and Goodier, C. (2013). Heat wave adaptations for UK dwellings and development of a retrofit toolkit. International Journal of Disaster Resilience in the Built Environment 4(3), 269-286.

PHE (2018). Public Health England. Heatwave plan for England Protecting health and reducing harm from severe heat and heatwaves.

Randall, C. (edited by Jen Beaumont). (2011). Housing. Office for National Statistics. London (UK).

Ravetz, J. (2008). State of the stock-What do we know about existing buildings and their future prospects? Energy Policy 36, 4462-4470.

Symonds, P., Taylor, J., Chalabi, Z., Mavrogianni, A., Davies, M., Hamilton, I., Vardoulakis, S., Heaviside, C. and Macintyre, H. (2016). Development of an England-wide indoor overheating and air pollution model using artificial neural networks. Journal of Building Performance Simulation 9(6), 606-619.

Symonds, P., Taylor, J., Mavrogianni, A., Davies, M., Shrubsole, C., Hamilton, I. and Chalabi, Z. (2017). Overheating in English dwellings: comparing modelled and monitored large-scale datasets. Building Research \& Information 45(1-2), 195-208.

Taylor, J., Wilkinson, P., Davies, M., Armstrong, B., Chalabi, Z., Mavrogianni, A., Symonds, P., Oikonomou, E. and Bohnenstengel, S. (2015). Mapping the effects of urban heat island, housing, and age on excess heat-related mortality in London. Urban Climate 14, 517-528.

U.S. DOE BTO (2017). EnergyPlus.

Weng, K. (2017). Performance of UK Dwellings in Projected Future Climates. Energy Procedia 105, 3727-3732.

WHO (1987). Health impact of low indoor temperatures: Report on a WHO meeting. WHO Regional Office for Europe, Copenhagen.

Wright, A., Young, A. and Natarajan, S. (2005). Dwelling temperature and comfort during the August 2003 heat wave. Building Services Engineering Research And Technology 26(4), 285-30. 